\title{
Role of Intramedullary Interlocking Nailing In Complex Femoral Shaft Fractures.
}

\author{
Dr. S. P. Ilangovan, Prof. V. Thulasiraman, \\ ${ }^{l}$ m.S (Orth). Chief Medical Officer, Esic Hospital \& Pgimsr, Chennai. India.600078, \\ ${ }^{2}$ m.S (Orth).Madras Medical College, Chennai, Tamilnadu, India.600003
}

\section{Introduction:}

Fractures of the shaft of femur are a major cause of morbidity and mortality in patients who sustain high energy trauma. Morbidity arises from limb shortening, malalignment, knee contractures and other complications of fracture. Mortality is infrequent but can result from an open wound, fat embolism, adult respiratory distress syndrome or multiple organ failure especially in the poly trauma patients. Both morbidity and mortality can be diminished by prompt reduction and internal fixation of the fracture. (Robert A .Hansen T.et al. 1978. $)^{1}$.

Restoration of alignment, rotation and length, preservation of the blood supply to aid union and rehabilitation of the patient are the goals of treatment. The type and location of the fracture, degree of communition, the age of the patient, patients social, economic demands and other associated fractures may influence the method of treatment.

Currently intramedullary, interlocking nailing is considered to be the treatment of choice for complex femoral shaft fractures. (Funk .J.Wells. R et al 1968.) ${ }^{2}$.

\section{Material And Methods}

Between October 2006- december 2009, all patients who had a complex fracture of the femoral shaft were seen in the government general hospital treated with intra medullary interlocking nailing were included in our study. Compound fractures, fractures in pediatric and adolescent age group, old fractures were excluded from our study. All the patients were thoroughly examined for associated injury and neurovascular damage. Thorough examination of the ipsilateral hip and knee was performed. All fractures were stabilized initially with Thomas splint, plaster immobilization and pin traction. All patients stabilized haemodynamically with intravenous fluids, blood transfusion as required.

Radiographic evaluation was done by obtaining anteroposterior and lateral views of femur, hip, knee as well as an anteroposterior view of the pelvis.

Data on clinical and radiological follow up to the time of union or non union of the fracture were collected for twenty patients. A segmental fracture was defined as a fracture of two separate levels, with the intermediate fragment with tubular structure.

There were nineteen males and one female patients, and the average age was thirty four years (range from eighteen to seventy eight years).The fracture was right side in eighteen patients and left side in two patients. High energy trauma secondary to motor vehicle accident in fifteen patients, low energy injuries due to the fall in five patients. Average time for nailing after the fracture was thirteen days.

All the patients were operated on regular operating table with open method except one patient who was operated with closed method. Reaming was done in all cases proximal and distal locking was done in all cases with the help of jig or C-arm.

Postoperatively, static quadriceps exercises and knee mobilization started on second postoperative day. Partial weight bearing was allowed for six weeks with crutches followed by progressive weight bearing as tolerated.

The time of union of fracture is defined as the time from the nailing to full weight bearing, with healing characterized by bridging callus seen on two radiographs made with different projection. Non union was considered to be present if there was pain at the fracture site, continued need for external support, absence of radiological evidence of healing. Mal union was defined as shortening or lengthening of more than one centimeter, 10 degrees or more in any plain, rotation misalignment of more than 15 degrees.

\section{Results}

Duration of follow up range from six to sixteen months.(average ten months). The results were analyzed with Thoresen .et al criteria. 
Role of Intramedullary Interlocking Nailing In Complex Femoral Shaft Fractures.

Classification-Thoresen et alss (Thoresen B.O, Alho A. JBJS 1985)

\begin{tabular}{|l|l|l|l|l|}
\hline Malalignment of femur & Excellent & good & fair & Poor \\
\hline Varus/valgus & $5 \mathrm{deg}$ & $5-9 \mathrm{deg}$ & $10 \mathrm{deg}$ & $>10 \mathrm{deg}$ \\
\hline Ante/recurvatum & $5 \mathrm{deg}$ & $10 \mathrm{deg}$ & $15 \mathrm{deg}$ & $>15 \mathrm{deg}$ \\
\hline Int/ext rotation & $5 \mathrm{deg}$ & $10 \mathrm{deg}$ & $15 \mathrm{deg}$ & $>15 \mathrm{deg}$ \\
\hline Rom flexion knee & $>130 \mathrm{deg}$ & $120 \mathrm{deg}$ & $90-119 \mathrm{deg}$ & $<90 \mathrm{deg}$ \\
\hline Shortening & $1 \mathrm{~cm}$ & $2 \mathrm{~cm}$ & $3 \mathrm{~cm}$ & $>3 \mathrm{~cm}$ \\
\hline Ext deficit & $5 \mathrm{deg}$ & $10 \mathrm{deg}$ & $15 \mathrm{deg}$ & $>15 \mathrm{deg}$ \\
\hline
\end{tabular}

There should be no pain and tenderness in the fracture site.

\section{Static interlocking nailing done in all case.}

All patients were followed by regularly and evaluated clinically and radiologically for fracture union and other complication. Primary bony union in 18 cases. Average time for bony union was 26 weeks. One case of delayed union of distal fracture site to whom cancellous bone grafting was done. Varus angulation was noted in three cases of distal third femoral shaft fractures. Rotatory malalignment was noted in one case. Two patients with associated injuries of fractures of both bone leg had significant knee stiffness. Two patients had wound infection. There was no implant failure was noted .Average knee flexion was 120 degrees. Average hip flexion was 125 degrees. Ten patients showed excellent functional results and there was no shortening, mal rotation, no pain or swelling in the fracture site. Movements of hip, knee were near normal in these patients. Five patients had good results with knee flexion of about 120 degrees. Three cases of fair results had knee flexion between 90-119 degrees. Two patients had poor results with limb shortening and knee flexion less than 90 degrees. Analysis of the results done with Thoresen et al criteria.

\section{Complications:}

1) Two patients had infection in which one patient had delayed infection after the period of 1 year for whom implant exit was done after the fracture union.

2) One patient had superficial infection to whom wound debridement and secondary suturing was done and patient had knee stiffness.

3) One patient had non union due to the mal positioning of distal locking screws and distal migration of the nail into the knee joint for which implant exit was done.

4) No implant failure was found in our series.

5) No neurovascular damage seen in our series.

\begin{tabular}{|l|l|l|}
\hline Results & In our study & Thoresen B.O. et al \\
\hline Excellent & $10(50 \%)$ & $30(64 \%)$ \\
\hline Good & $5(25 \%)$ & $8(17 \%)$ \\
\hline Fair & $3(15 \%)$ & $7(15 \%)$ \\
\hline Poor & $2(10 \%)$ & $2(4 \%)$ \\
\hline
\end{tabular}

\section{Illustrative Cases;}

Case-1. 34 years old male, H/O RTA had segmental \# shaft of femur RT side, treated with intramedullary interlocking nail.

Fig-1

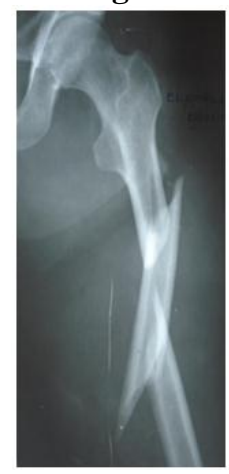

Fig-2

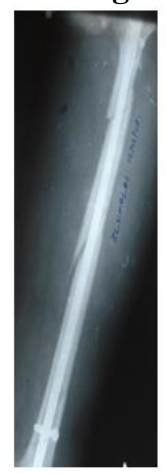

Fig-3

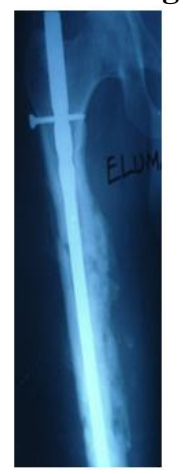

Fig-4

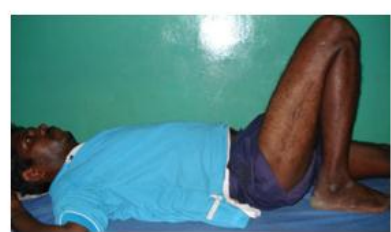



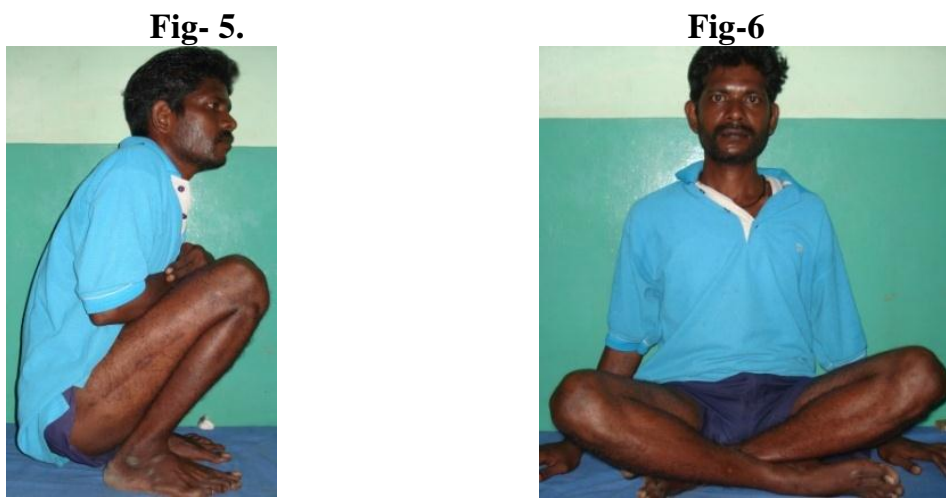

FIG-1.pre op AP view

FIG-2.post op AP view

FIG-3.post op six months follow up with fracture union.

FIG- 4-6. functional outcome.

\section{CASE -2}

36 years old male, H/O RTA had segmental \# shaft of femur RT side . Treated with intramedullary interlocking nail.

Fig-1

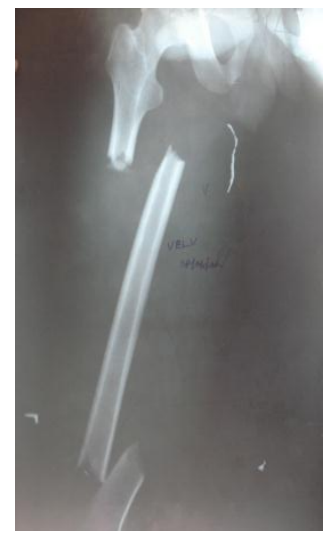

Fig-3

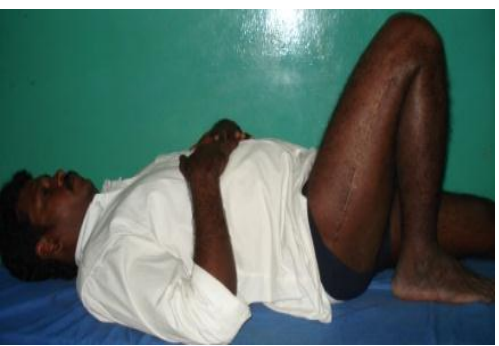

Fig-2

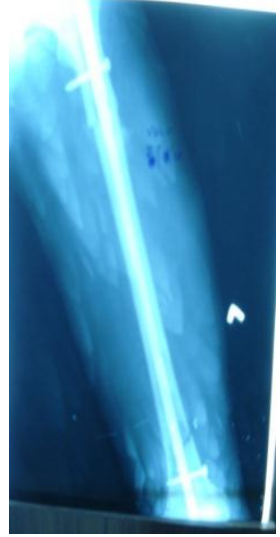

Fig-4

Fig-5
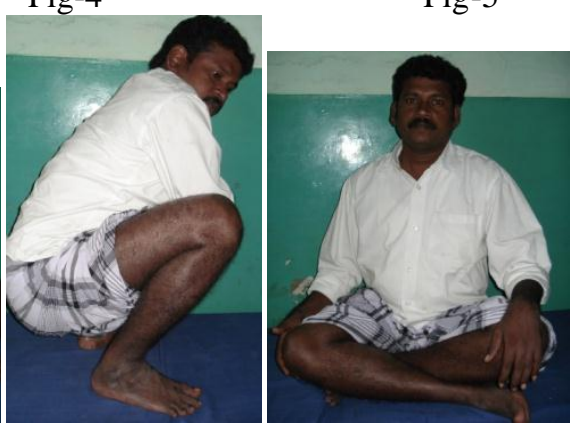

Fig-1. Pre Op Ap

Fig-2 .Post Op Ap 1 Month Follow Up

Fig-3 -5 Functional Outcome

\section{Discussion}

Fractures of the shaft of femur usually a result of high energy trauma and accompanied by severe injuries to other organ system. The therapeutic goals in the treatment of this fracture are avoidance of cardiopulmonary problems, prevention of infection, early mobilization and functional rehabilitation of the limb. 
(B.O. Thoresen,Alho.A et al) ${ }^{3}$ 1985.Complex femoral fractures are uncommon and usually caused by high energy violence. (Winquist and Hansen et al) ${ }^{4}$. 1984. Incidence is $1-5 \%$ of femoral shaft fractures. (Church J .C .T et al 1971. ${ }^{5}$, Wu C. C ,Shih C.H et al 1993 et al). ${ }^{6}$

We considered fracture to be united when there is no tenderness or pain during weight bearing and when there is radiographic bridging callus with cortical density connecting three segments. (Wu.C.C, Wen .J.C. et al 1997. $)^{7}$

Intramedullary interlocking nailing has proved to be the effective method in the treatment of the complex fracture shaft of femur in adults. Since the femur is surrounded by muscles and excellent soft tissue coverage, the destruction of endosteal blood supply due to reaming does not impede the fracture healing. Intramedullary interlocking nail acts as an internal splint and provide rigidity and rotational stability. (B.O. Thoresen, A .Alho et al) ${ }^{3 .} 1985$.

Segmental fracture of femur is an unusual injury caused by a severe force and associated with marked damage to the soft tissue especially quadriceps muscle. Since the patient who incur this type of fracture frequently have associated multiple injuries ,stabilization of patient is the first objective in treatment, but the two subsequent goals, bone union despite diminished vascularity and restoration of function despite excessive soft tissue damage. (Robert. A. Winquist, Washington .S. et al 1978) ${ }^{8}$. In segmental fractures union of the distal segment is delayed in some cases. In our study one patient had delay in fracture healing in the distal fragment to whom bone grafting was done.

In segmental fractures there is always a substantial soft tissue injury. (Rinaldi E, Nurra A et al 1989). ${ }^{9}$ The vascular supply of the distal segment is reduced in the segmental fractures. Therefore the healing of the distal fragment is usually slower. Weight bearing has been widely used to promote the fracture healing. Dynamization promotes union of fracture site in $50 \%$ of delayed union cases. Early bone grafting yield $100 \%$ fracture union ( Wu CC.,. Wen- JC et al 1997). ${ }^{7}$ In our series three cases of segmental shaft of femurs were treated with primary bone grafting united in an average period of 26 weeks against 32 weeks in non bone grafted individuals.

Allogenic cacellous bone grafts can be used to augment the healing of fresh fractures associated with bone loss or non-union in conjunction with autologous bone graft. Osteogenic protein -1 can be used in recalcitrant non union.

The use of plate to achieve osteosynthesis of segmental fractures necessitate a wide operative exposure and excessive stripping of soft tissues resulting in an increased blood loss and long operating time. The risk of infection and delayed union is increased and failure of the plate is also common. Due to high rate of complications associated with this type of fixation, most of the traumatologists have advocated intramedullary interlocking nailing is the gold standard treatment. Early mobilization is thought to reduce the post operative complications, to maintain joint motion and to decrease the hospital stay.

All the cases patients are operated on standard radiolucent operating table using manual traction. The main advantage of this technique is that injuries of other extremities could be efficiently managed without the need for patient transfer.

Use of fracture table is associated with pudendal, sciatic, femoral nerve palsies due to traction or direct pressure. In addition compartment syndrome in well leg and crush syndromes have been documented with the use of fracture table and probably caused by intra operative positioning.(D.A. Weiss , WW. Brien 1990 et al) ${ }^{10 .}$

In our series there was no neurovascular damage occurred during surgical procedure on radiolucent table. D.A. Weiss, WW. Brien et al $1990^{10}$. study of interlocking nailing in segmental shaft of femur fractures in 33 patients they recorded two nerve palsies secondary to traction injury during intra medullary nailing in the fracture table, one each of the sciatic nerve and the pudendal nerve which were recovered completely within seven months.

Our study consists of 19 cases of complex femoral fractures were treated by the open interlocking nailing and one case by closed nailing. The mean duration between the injury and surgery is higher in our institution (average 17 days) due to patient reporting to our hospital after native treatment, non availability of theatre time due to long waiting list, and associated co-morbid conditions.

This longer duration between the time of injury and surgery is accounted for difficulty in fracture reduction with consequent opening of the fracture site. This time is higher against Thorsen. BO, Alho A. et al $1985 .^{3}$ series where it was 3 days and in Wu CC, Wen JC et al $1997^{7}$ study it was 1 day.

The patient who had close nailing, showed early fracture union in 20 weeks and functional outcome was excellent.

Static interlocking nailing was done in all 20 cases. Brumback R.J., Poka A. et al $1988 .{ }^{11}$ concluded in their series that static locking of intramedullary nails in femoral shaft fractures does not inhibit the process of healing of fracture and routine conversion to dynamic intramedullary fixation although necessary need not performed always. 
In segmental fractures the danger of devitalization of the intermediate free fragment is lessened by mediculous soft tissue handling and avoidance of periosteal stripping. There is a theoretical risk of spinning of central fragment during reaming, there by damaging blood supply and delaying healing. Donald. A. Weiss. William. A. Brien et al 1990. ${ }^{10}$ study shows strong attachment of soft tissues along the linea aspera prevents spinning in most of the cases. However, when the intermediate fragment is less than $10 \mathrm{~cm}$ length, spinning is a risk, and reaming should be done slowly and carefully.

The debris created during intramedullary reaming was shown to be collected at the fracture gap. This effect was also comparable with conventional bone grafting, thus supporting the theory of autografting. Reaming mobilizes cancellous bone inside the medullary canal. (Olerud R, stromberg L.et al 1986.) ${ }^{12}$

The reaming debris is a source of multipotent stem cells which can grow and proliferate and transform into various type of cells. In a quantitative assessment of growth factors in reamed aspirate, elevated levels of several growth factors were found in the debris as compared with bone graft from the iliac crest. The process of reaming induced an increased of further growth factors by $111 \%$.

In our series reaming was done in all cases and all fractures united with an average period of 26 weeks. Average age of incidence is 35 years. This is comparable with Donald .A. Hansen T et al 1978. ${ }^{1}$ study in which it was 31 years. Average age of incidence in was 38 years, in Wu CC, Wen JC et al $1997^{7}$ was 37 years

60 percent of the fracture in our series located in middle third.

$15 \%$ of our patients suffered complex femoral fractures due to low energy injury and most of the patients were elderly individuals.

In younger patients with low energy injury, fracture united in an average period of 19 weeks. In older patient who had low energy injury, fracture united in an average period of 32 weeks. It may be due to co morbid conditions in the older age and delayed weight bearing.

\section{Bone grafting:-}

Cancellous bone graft is usually harvested from iliac crest, distal radius, greater trochanter, proximal tibial and distal femoral metaphysis.(Goldberg V M, Steven S et al 1989) ${ }^{13 .}$ It is an excellent choice for the treatment of conditions that do not require structural integrity from bone graft.(Enneking W F, Moore J R et al.1990 $)^{14}$.Cancellous bone graft has osteo conductive, osteo inductive potential. It contain osteoprogenitor cells.

Primary bone grafting was done in comminuted fractures. Three cases of segmental shaft of femur fractures treated with interlocking nail and bone grafting was united well in an average period of 24 weeks against the average of 32 weeks in non bone grafted individuals.

Three cases of comminuted fractures which were treated with interlocking nail and primary bone grafting united well in an average period of 21 weeks against 24 weeks

Average amount of intra operative blood loss in the segmental shaft of femur fractures in 580ml ,(range $450 \mathrm{ml}-800 \mathrm{ml}$ ) which was higher in our study in compare with D.A. Weiss WW.Brien et al ${ }^{10}$. 1990 . study, in which it was about $470 \mathrm{ml}$. It may be due to time delay for the operative procedure from the date of injury.

In our series we had 2 cases of post operative infection one is superficial wound infection, which was treated with wound debridement and secondary suturing and wound healed well with secondary intention but the patient had knee stiffness. One case of late infection after the period of one year to whom implant exit, debridement done and external fixator was applied .

In D.A. Weiss,WW.Brien et $\mathrm{al}^{10} 1990$ and Wu CC, Wen JC et al $1997^{7}$ study they had no infection in 33 cases, 56 cases respectively. Winquist. RA. Hansen $\mathrm{T}^{8}$ et al 1978. stated that open interlocking nailing involves the risk of infection. In our series we had two cases of post operative infection which may be due to open nailing.

$15 \%$ of cases in our study had varus malalignment. All three cases had fractures involving the distal third of femur with comminution. In D.A. Weiss,WW.Brien et $\mathrm{al}^{10} 1990$ study $5 \%$ cases had postoperative mal alignment. In Wu CC, Wen JC et al $1997^{7}$ study no cases of malalignment was reported.

Due to comminution and presence of wide medullary canal in the distal third femur could be the cause for varus deformity. It can be prevented by the use of poller screws, double distal locking, cylinder cast or cast bracing.

In our study seventy five percent had knee flexion more than 120 degrees and had good functional outcome. Most of the cases operated earlier and post operative knee mobilization, quadriceps exercises were started on second post operative period and had good results. $10 \%$ of cases had associated ipsilateral fracture both bone leg and had poor knee flexion with average of 92 degree and these patients had poor fair results. In D.A. Weiss, WW Brien et $\mathrm{al}^{10}$ 1990. study average knee flexion was 130 degree. In Winquist RA., Hansen. T $1978{ }^{8}$ Study the average knee flexion was 135 degree which was higher than our study. Average knee flexion in our study was 119 degree. So early stabilization of fractures and early rehabilitation yield excellent functional outcome. 
Donald A. Weiss.,WW Brien et $\mathrm{al}^{10} 1990$ concluded that virtually all fracture distal to lesser trochanter can be nailed regardless of pattern of fracture and degree of communition. This supports the role of stable fixation in facilitating union in the complex femoral shaft fractures.

\section{Conclusion}

Our Study Consists Mostly Of Male Patients In Their Active Part Of Their Life. So, There Is A Need For Quick Return Of Their Daily Routines. Intramedullary Interlocking Nailing For Complex Femoral Fractures Has Been Established World Wide As The Gold Standard Treatment Because Of Its Load Sharing Property, Internal Splinting, And Rotational Stability. These Contribute The Stable Osteosynthesis.

When The Patients Are Taken Up For Surgery Earlier, Fracture Reduction Can Be Achieved By Closed Method And Yield Early Fracture Union, Excellent Functional Outcome And Prevention Of Complications.

Early Mobility, A Low Rate Of Complications And High Incidence Of Union Obtained In This Study In Majority Of Patients Makes This Technique More Reliable.

\section{Bibliography}

[1]. Robert A, Hansen .T. Segmental Fracture S Of Shaft Of Femur Treated By Closed Intramedullary Nailing. T.JBJS Vol 60A 934-939. Oct 1978.

[2]. $\quad$ Funk.J, Wells .R Supplementary Fixation Femoral Fractures.Clin.Ortho. 60; 4-49.1968.

[3]. Thoresen BO, Alho A., Intramedullary Interlocking Nailing In Femoral Shaft Fractures A Report Of Fourty Cases. JBJS 1985; 67; 1313-1320.

[4]. Winquist RA, Hansen S. Closed Intramedullary Nailing Of Femoral Fractures. A Report Of 520 Cases. JBJS 66-A 529-539.1984.

[5]. Church Jct.Segmental Fractures Of Femure, JBJS 1971; 53(2): 355.

[6]. Wu CC, Shin CH, Ueng WN. Treatment Of Segmental Femoral Shaft Fractures. Clin Orthop 1993; 287; 224-30.

[7]. Wu CC, Wen JC Et Al. Healing Of 56f Segmental Femoral Shaft Fractures After Locked Nailing. Acta Orthop Scand 1997; 68m(6): 537-540.

[8]. Robert A, Washington S.Segmental Fractures Of Femur Treated By Closed Intremedullary Nailing JBJS, 1974, 72: 534-554

[9]. Rinaldi E, Nurra A.Mulfifocal Fractures Of The Femur, Ital Of Orthop Traumatol 1989; 15 (4): 409-414.

[10]. Wiss DA, Brien WW, Stentson WB, JBJS 1990; 72: 724-728.

[11]. Brumback RJ, Lakatos RP, Poka A.Bathon GH, Burgess AR Intramedullary Nailing Of Femoral Shaft Fractures. Fracture Healing With Static Interlocking Fixation. JBJS 1988; 70 (10): 1453-62.

[12]. Olerud S.Stromberg. L Intramedullary Reaming And Mailing Its Early Effects On Cortical Bone Vascularization. Orthopedics 1986; 9 (9): 1204-1208.

[13]. Goldberg VM, Sreven S.The Biology Of Bone Graft Repair. Semin Arthroplasty, 1989; 7:12.

[14]. Enneking WF, Moore JR, Burcherdt H, Physical And Biological Repair In Cortical Bone Transplants. JBJS - 1990; 57: 237-252. 